\title{
Actors' Dynamic Value Co-creation and Co-destruction Behavior in Service Systems: A Structured Literature Review
}

\author{
Li Mengcheng \\ University of Jyväskylä \\ Faculty of Information Technology \\ mengcheng.m.li@student.jyu.fi
}

\author{
Tuunanen Tuure \\ University of Jyväskylä \\ Faculty of Information Technology \\ tuure@tuunanen.fi
}

\begin{abstract}
This paper investigates resource integration and social interaction as the two core processes of value co-creation and co-destruction in a service system. We applied a structured literature review as our research methodology to develop a framework to depict the components of value co-creation and co-destruction processes and to understand the behavioral drivers of service system actors as well as the positive and negative value outcomes derived through resource integration and social interaction. By analyzing the 51 papers that meet the inclusion criteria, we found that actors' engagement in value creation process are motivated by different behavioral drivers. Then, applying resource integration, and more specifically, access, matching, and resourcing, actors interact through social interaction employing communication, dialogue, and trust contribute to the dynamic process of value co-creation and co-destruction embedded on context-based practices, which leads to actors' unique perceived value outcomes.
\end{abstract}

\section{Introduction}

Value co-creation (VCC) is an increasingly important strategy for organizations seeking a competitive advantage developing and offering service systems to markets [1], namely because it contributes to cost reduction [2], time savings [3], and increased satisfaction in service settings [4]. VCC not only drives service innovation and evolution within the market, but also enables the generation of new knowledge in business, academia, and practice [5].

To better manage co-creation of value and benefit from it, it is important for engagers to have a deep understanding of the processes of VCC and the drivers of actors who are part of the service system. As the basic unit of analysis of service, service systems are defined as 'value-co-creation configurations of people, technology, value propositions connecting internal and external service systems, and shared information (e.g., language, laws, measures, and methods)' $[6, \mathrm{p} .18]$. The smallest service system can be individual level as interactions take place, and the largest service system can comprise the global economy. In this research, we adopt the term 'actor', instead of customers, providers or any other specific party involved in the service system because they engage in the same process and each actor can have different roles and motivations.

Since Kambil, Ginsberg, and Bloch [7] coined the term "value co-creation" to emphasize customer's role in business strategy and marketing, the term has been defined by many authors. Grönroos [3] defined VCC as a function of interaction when customers create value in use while Lusch el al. [8] mentioned that value creation occurs 'when a potential resource is turned into a specific benefit'. The present study uses the definition by Barile and Saviano [9], in which VCC implies that several actors engage in the same process for mutual benefit with different perspectives and finalities. This definition is representative since it emphasis the important concept 'co' in 'value cocreation'. In order to 'co'-create value, actors must participate, be engaged, relate to each other and be active in the process.

VCC has long been studied from various perspectives, including marketing, services, design, innovation and new product development, and management [10]. However, researchers have only recently begun studying the corresponding phenomenon known as value co-destruction (VCD) e.g.[11-13]. VCD is conceptualized as "an interactional process between service systems that results in a decline in at least one of the systems' wellbeing (which, given the nature of a service system, can be individual or organizational)" [15, p. 431]. The argument coming from this literature is that actors' collaboration in service systems not only yields beneficial outcomes, but also can result in the co- 
destruction of value for the actors involved [13]. Thus, the VCD is argued to be an integral part of the interactions among actors, like the co-creation of value [11]. It has been suggested that VCC and VCD are two key dimensions of the value creation [11] while research on the negative side of $\mathrm{VCC}$, or $\mathrm{VCD}$, is scant [14]. Vartiainen and Tuunanen [15] argued that VCC and VCD are linked and cannot exist without the other. If this is true, the processes of VCC and VCD should be studied within the same setting, the likes of which is rare in the current literature.

Currently there are two mainstreams of approaches to understand value co-creation in service settings, namely Service Dominant Logic (SDL) and Service Logic (SL). Each approach employs a set of foundational premises or constructs to depict its logic, which influence how co-creation is explained and portrayed [16]. SDL proposes that 'Value is co-created by multiple actors, always including the beneficiary' and it implies that value is interactional [17, p.8]. Operant resources are considered to be the fundamental source of strategic benefit and value is co-created by the service offer(er) and the service beneficiary through resource integration [17]. SL divides value creation and formation process into three spheres: a provider sphere, a customer sphere, and a joint sphere [16]. VCC is defined to be a joint process taking place on a co-creation platform involving 'service provider's service (production) process and the customer's consumption and value creation process merge into one process of direct interactions' [16, p.87]. Actors create value in the form of value-in-use, by integrating new resources with existing resources using knowledge and skills [16]. Despite of the different understandings and descriptions about VCC, SDL and SL share the commons that they both recognize the importance of resource integration and interactions for co-creating value in service settings, which provide an interesting perspective for our research.

The extant literature also agrees that resource integration and social interactions are fundamental for value formation process. Letaifa [18] presents that VCC is inherently a social process and thus requires social interaction. High-quality interactions among actors who enable the co-creation of unique experiences are the key to forming competitive advantage [2]. VCD also occurs during social interaction without sufficient communication [19], trust and well-structured dialogue [20] . During the codestruction process, actors conduct social interaction directly or indirectly through the integration and application of resources. Any incongruent elements of practice and inappropriate or unexpected behavior [21] during this process can result in VCD. In the same vein, resource integration is viewed as an embedded part of VCC [22]. Intended, unintended, or negative value emerges through resource integration and active doing depending on the alignment or misalignment between and within the practice of communities [22]. The fit between resources integration contributes to VCC while VCD is triggered by failing in resource integration process when trying to co-create expected value [23].

Gummesson and Mele [24] asserted that VCC is a time-based process in which the underlying two core phases are actor-to-actor interaction and the integration of actor resources in terms of the engaged actors' expectations, capabilities, and processes. In addition, Vargo and Lusch [25] and Fyrberg Yngfalk [26] also agreed that VCC is indeed a process of multidirectional resource integration and multiple interactions. Such perspectives demand that resource integration and social interaction being discussed systematically in the broader context of relationships and networks [24]. We posit that VCD should also be discussed in this same setting.

However, no study to date has adopted both resource integration and social interaction to explain VCC and VCD simultaneously. In order to understand the drivers of VCC and VCD through resource integration and social interaction, it is imperative to summarize what have been done and found by previous studies, while the study of such does not exist yet to the best of our knowledge. Therefore, to fill the recognized research gap, the present study applies a structured literature review focusing on resource integration and social interaction as the key processes of VCC and VCD. Consequently, the objective of this paper is to develop a conceptual framework to depict the components of VCC and VCD processes and to understand the drivers of their positive and negative outcomes in a service system focusing on resource integration and social interaction. This is important since it could provide a systematic understanding of the VCC and VCD processes and may be helpful for creating value by maximizing benefits and preventing unwanted outcomes for actors in a service system.

The paper is structured as follows. Next, we go through the applied structured literature review methodology. Thereafter, we present our findings and developed framework for VCC and VCD process in service systems. Finally, we discuss the implications of our work, conclude and discuss future research.

\section{Research methodology}


Table 1. An example of articles included in the review

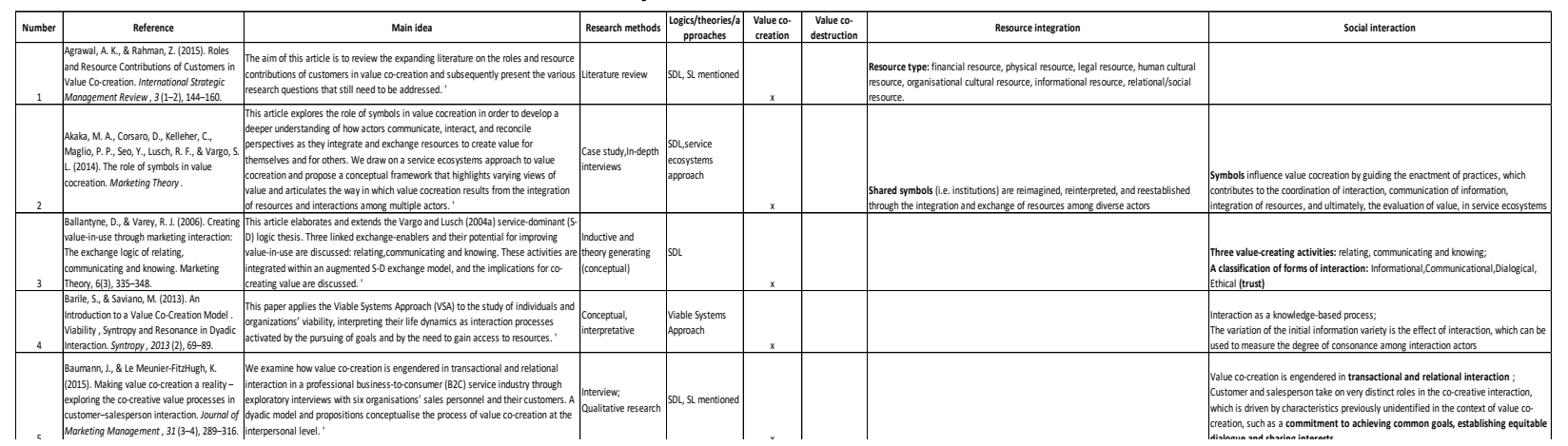

Our study applies a structured literature review as its research methodology [27], [28] to facilitate theory development by synthesizing the existing literature about VCC and VCD in terms of resource integration and social interaction. The structured literature review was conducted through seven steps (see Figure 1). Keyword searches were carried out in three interdisciplinary and complementary databases: Proquest, Science Direct and Google Scholar.

Specifically, four pairs of keywords (in abstract) were used in those three databases as shown in steps 13: 'value co-creation' \& 'resource integration'; 'value co-creation' \& 'social interaction'; 'value codestruction' \& 'resource integration'; 'value codestruction' \& 'social interaction'. 462 articles were retrieved (step 4) from the first three steps.

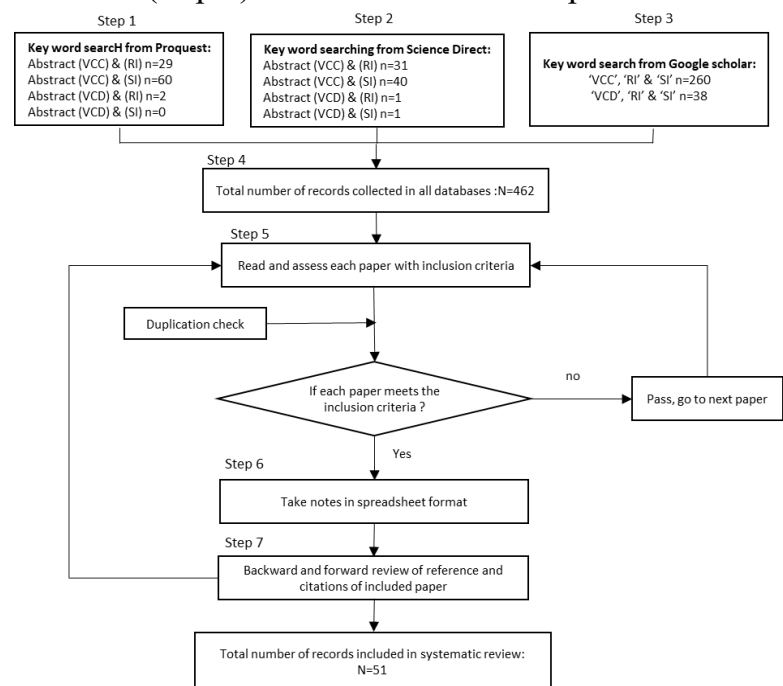

Figure 1. The applied structured literature review methodology

Then in step 5, the retrieved articles were read and assessed with the following inclusion criteria: 1 . The article must focus on studying VCC or VCD; 2 . The article must discuss resource integration or/and social interaction efficiently. The full text should be available online and peer-reviewed (thus thesis is not included).
Repeated papers were detected during this phase. When assessing and analyzing each included article, extensive notes were taken in a spreadsheet format about the articles' main ideas, theories/logics, methods, ideas related to resource integration and social interaction in step 6 .

In step 7, we reviewed backward and forward the references and citation indexes of included papers to find additional relevant articles, which were then vetted using the same criteria outlined in Step 5.

The final number of papers that meet the inclusion criteria is 51 . Table 1 gives an example of the first 5 included papers ordered alphabetically to show how those articles meet the inclusion criteria and how our framework is related to the literature. Due space limitations, we report here only a selection of the key arguments made in the extant literature based on our research objective. The complete information is available by request from the authors.

\section{Findings}

Among the 51 included papers, 28 of them adopt a conceptual study (such as literature review) and others adopt an empirical study (mainly based on qualitative analysis of interview data, one paper collects data using survey and one through observation). 38 out of the 51 papers use SDL as the main logic to understand related phenomenon, while eight of them mention about SL. Other theoretical approaches such as practice theory, social construction theories, motivation theory, consumer culture theory, resource-advantage theory, resource-based theory, social learning theory, social exchange theory, role theory, social resource theory are used in the included papers.

There are 48 out of 51papers focusing on VCC while only 16 articles discussing about VCD, among which 13 papers covering both. The discussion about resource integration and social interaction appears to be similar in terms of number of articles included (32 and 30 respectively). Specifically, resource integration 
has been discussed mainly from the following perspectives: 1. resource/resource integration types e.g. [29], [30]; 2. resource integration practices/activities/drivers e.g. [22], [23], [31]. ; 3. the importance of resource integration towards value creation process e.g. [14], [32], [33]. While social interaction has been discussed mainly from: 1 . interaction types e.g. [11], [34], [35]; 2. interaction process/practices/drivers e.g. [19], [36], [37]; 3. the importance of social interaction towards value creation process e.g. [13], [32]. In addition, some of the articles also discuss the role actors play in the process of VCC and VCD and actors' motivations of engagement [23], [38], [39]. 12 papers discuss both resource integration and social interactions, mainly focus on their importance for value creation process.

Since our objective is to develop a framework depicting how the process of resource integration and social interaction contribute to VCC and VCD for actors in the service system, the types and importance of resource integration and social interaction will not be included into the framework. However, those two dimensions will still be discussed to better cover the ideas from reviewed literatures and provide fundamental explanation about the value creation process. By analyzing the 51 included papers based on our research objective, we found that VCC and VCD are triggered in three interacting dimensions-actors' behavioral drivers, resource integration and social interaction processes, and value outcomes - and their components depict VCC and VCD processes. The actors' behavioral drivers dimension indicates that different participants engage in the same collaborative process in a service system with different roles and motivations. The resource integration and social interaction processes focus on how these contribute to dynamic VCC and VCD in the service system. The value outcomes dimension emphasizes the actors' perceived assessments of the value outcomes. Figure 2 summarizes the key findings into a framework that represents a systematic view of the VCC and VCD process. In the following, we will discuss the framework in detail.

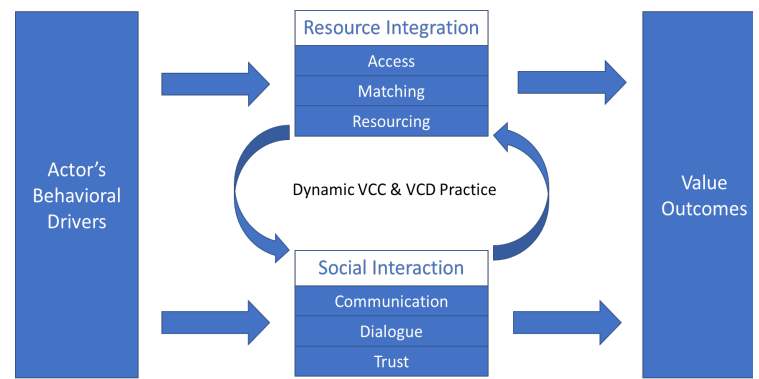

Figure 2. Dynamic Value Co-creation and Codestruction bv Service Svstem Actors

\subsection{Actors' Behavioral Drivers}

Since Vargo and Lusch [40] published their paper regarding a need of shifting our focus from parties with pre-designated roles to generic actors, many authors e.g. [41] have adopted the word "actors" to represent enterprises engaging in the process of providing mutual benefits through exchange activities, directly or indirectly. Storbacka et al. [31, p.3010] asserted that "actors need to be viewed not only as humans, but also as machines/technologies, or collections of humans and machines/technologies, including organizations".

In this paper, "actors", are defined as organizations or persons having similar processes of engagement [42], and one actor can have different roles in the service system. For instance, Agrawal and Rahman [10] stated that customers can play the role of coproducer, co-distributor, co-promoter, comanufacturer, co-consumer, experience creator, coinnovator, co-ideator, co-evaluator, co-designer and co-tester in VCC. The term 'actor' also highlights the action, interaction, and engagement required for effective VCC [42].

Different actors participate in VCC activities with different behavioral drivers (motivations); namely, the willingness, desire, and interest of these actors to engage in the process in a co-creation context [43]. Drivers behind VCC can be categorized from different perspectives. Oreg and Nov [44] stressed that personality and contextual factors such as reputation and altruism are important motivations of individual's contribution. Some researchers studied the drivers behind actors' co-creation behavior from the costbenefit perspective. For example, Nambisan and Baron [45] identified four kinds of benefits that drive customer to participate in a virtual community including cognitive, hedonic, personal integrative and social integrative benefits.

Behavioral drivers are important for understanding actors' engagement in resource integration and social interaction. Findsrud et al. [38] identified motivation as vital factors of the explanation of how and why actors engage in the resource integration processes. Motivation is an important driver of activity, as it determines the direction (activities the actors choose to engage), intensity (efforts the actors put into the activities), and persistence of effort (continual engagement despite of negative experience) toward resource integration [38]. These factors also drive actors to participate in innovation projects and social interaction activities such as networking [46]. Conflict and reduced motivation, on the other hand, can lead to value destruction in terms of actors' interaction experience and value outcome [47]. For example, Stieler et al. [39] shows how value is co-created or co- 
destroyed depending on actors value expectation during interaction in the sport stadium. Therefore, knowing the actors' behavior drivers enables us to better understand how and why actors engage in VCC and VCD processes in a service system.

\subsection{Resource Integration}

Resources are often classified based on different perspectives. With the Service Dominant Logic, Vargo and Lusch [48] observed two kinds of resourcesoperand and operant, stating that goods are operand resources creating value through exchanges in traditional good-dominant logic. Operant resources are a combination of skills, knowledge and competencies acting on operand resources to create value for the firm, for example the ability to operate the technology [48]. Later, Arnould, Price, and Malshe [49] proposed a new understanding by combining consumers' operand and operant resources through customers' experiences and cultural perspectives. Resources thus can be further divided into social, cultural, and physical resources [49]-[51].

Resource integration can be characterized as a complementarity, redundancy, or mixing, depending on the similarities or differences of the actors' resources [24]. The resource integration process can be rich in complex service contexts, where actors engage in interactions and influence each other's experiences and value processes iteratively over time [29]. The integration process is also an opportunity to not just create new resources, but also to modify the potential resources that are available for further resource integration in the next stage [30].

According to Kaur et al. [33], resource integration predicts VCC by significantly influencing customer participation. Caridà, Edvardsson, and Colurcio [22], [31] in turn argued that resource integration should be viewed as an integrated and embedded part of the VCC process as emerging from three activities: the integration of resources, operations on resources, and the assessment of value. The value emerging from this process can be positive or negative, depending on the alignment or misalignment of the actor's resource. Akaka, Vargo, and Lusch [41] also stated that some contributions in the network perspective value are driven by the actor's capability to access, adapt, and integrate resources through routine practices within networks. Thus, value is co-created or co-destructed and assessed in use and is the outcome of activities and interactions (practices) in which resources are integrated [36]. Various peripheral practices enable the transition between VCC and VCD [52]. For instance, reporting and voluntary actions from any individuals can help firms quickly identify or even solve problems in the resource misintegration or nonintegration process, which can turn the situation to successful integration for VCC.

3.2.1. VCC \& VCD Drivers of resource integration. Based on the literature review, we summarize that access, matching and resourcing are the key factors of resource integration contributing to VCC and VCD.

Grönroos [3] stated that service experiences is dependent of the accessibility of resources. Access refers here to making resources such as knowledge and tools available so that the involved actors can co-create effectively in the service system [51]. Actors can better cooperate and co-create value in context based on their needs and requirements when there are accesses to multifaceted expertise [50]. Access to information can balance information asymmetry and improve information transparency. For instance, in the setting of health services, information asymmetry can be diminished by offering access to expert information and data to patients and therapists, thus improving informational transparency [53] and promoting VCC. Conversely, VCD can occur without sufficient access to adequate resources in time. For instance, if actors cannot share the same knowledge base and network tools, they may misinterpret or misunderstand information, which may result in misbehavior, thus destroying the well-being of the service system.

The matching of resources, activities, and processes is interpreted as the core of resource integration and the main mechanism for VCC [24]. Matching represents the fitness of available resources to mobilize and enable higher resource density and constructive interactions through dialogue [24]. According to Caridà et al. [31], matching is the pre-phase of the resource integration process based on interaction, which enables actors to share ideas, knowledge, and experiences [24]. However, sometimes the highly cocreated services may fail and could contribute to negative disconfirmation and dissatisfaction [54]. Misalignment/mismatching of practices is considered to be the major contributor of the failure of VCC in firm-brand virtual communities [55]. Factors such as lacking rules or feedbacks during the procedures may lead to the misalignment between actor's understanding and engagement. Thus co-creation of value happens when resources are aligned or matched well; otherwise, co-destruction of value takes place when the enactments misalign [22], [55].

Resourcing refers to actors' operations on the available resources, focusing on resource creation, integration, and the removal of resistance to turn potential resources into specific benefits [25], [30]. During resourcing, basic operant resources transfer into higher-order resources (composite operant resources 
and interconnected operant resources) through interaction. According to Paredes et al. [30], a higherorder resource can improve the sustainability of competitive advantage and commitment to resources.

However, VCD can also occur to service systems in the resourcing process. Plé and Chumpitaz Cáceres [13] and Smith [23] pointed out that inappropriate or unexpected use of the available resources can decline at least one of the actors' wellbeing in the service system. The misuse of resources can be explained as at least one of the actors fail in integrating or applying the available resources in an expected or appropriate way no matter it is accidental or intentional [13], [47]. In addition, gaining or loss of resource links to actors' well-being and affects the actors' ability to access and adapt other resources [23]. Loss of resources occurs when expected resources are not gained or the loss of resources exceed expectation, resulting in VCD [47].

\subsection{Social Interaction}

Social interaction represents a two-way, concurrent conversation among actors in a collaborative environment [46]. In other words, interaction is a 'mutual or reciprocal action where two or more parties have an effect upon on another' [56]. Six types of VCC interactions among actors were identified and justified by Karpen et al. [57], namely individuating, relating, empowering, ethical, developmental and concerted interactions. Those interactions are built on the idea actors collaborate aiming to facilitate reciprocal benefits [57]. While Baumann et al. [20] recognized two aggregation levels of interaction between buyers and sellers- transactional interaction and relational interaction-based on short-term or long-term relationship.

Social interaction is important for the co-creation of value as a "generator of experience and value-in-use" for the service system [35, p.336]. Specifically, social interaction enables actors to enter, support, and benefit from the value-creating processes of other parties [24]. Thus no value co-creation is possible without direct interaction among service systems [58]. Furthermore, social interaction empowers individuals and fosters collective decision-making in networks given the dynamics of relationships [46]. For instance, community members feel more confident in sharing information and providing feedback through social interaction [46], which in turn promotes VCC.

Nevertheless, some scholars critic that VCD is just another possible outcome of actors' social interactions [11], [13]. Based on the sociocultural view, various kinds of resistances could arise during actor interactions, such as activism and hooliganism [26]. Once the interaction is disorderly and inconsistent, the
VCC process needs to be adjusted and reformulated continuously, otherwise value would be co-destructed [26].

\subsubsection{VCC \& VCD Drivers of Social Interaction.}

Through the literature review, we conclude that in order to have an efficient social interaction and to cocreate value, actors need to build up a dialogue and it is important to have sufficient communication and build trust within the interactions.

Communication is the core of social interaction and works as a foundation in transferring information among actors [37]. The expectations and goals of the process as well as the rules of engagement are determined during communications [19]. Thus, strategic communication is held as essential for cocreation through clearly defining the situation [19].

With sufficient communications, actors can participate in the process of VCC with adequate understanding of the event and their expected roles in the process[19]. Specifically, a sufficient communication during interactions can be characterized by communication frequency, directionality and content relevance, which are identified to positively influence VCC [63]. In addition, communicative skills such as attentiveness, perceptiveness and responsiveness are found to be essential in supporting customers' value formation during communication [59].

Conversely, actors may not be able to achieve the goal or need extra efforts with the inadequate or lack of communication [47], [60]. The interaction between actors may fail since actors are not able to know their expected tasks and responsibilities during the collaboration with insufficient communication [19], thus may resulting in frustration and loss of time [60]. For instance, if an actor is not a good listener and does not attempt to understand other actors and/or give response to them during the interaction, VCD occurs due to dissatisfaction and misunderstandings.

Dialogue in turn provides a conversational platform where knowledge and other resources are transferred, and learning takes place [24]. Through dialogue, actors can exchange ideas, ask for help and share experience to engender successful value realization [20]. For instance, companies provide word-of-mouth channels where customers can comment on products or services, and discuss their purchasing and using experiences with others, thus value is co-created as actors can communicate and get feedbacks through dialogue. However, VCD can take place when the dialogues are not available in time for actors to interact with each other and when the channel is information asymmetry. It is difficult to build a dialogue if actors do not have the same access and transparency to information [2]. 
Lack of common understanding or lack of fairness would occur when those mismatches among actors exist [55]. Conflicts may also occur if the dialogue is used inappropriately, e.g. spreading unfair and negative word-of-mouth among consumers [60].

Trust, or confidence, in an exchange partner's reliability and integrity [61], is essential to the successful establishment of a co-creation. Trust is greatly valued by consumers, as it reduces the cost of anxiety associated with provision and perceived risk [62]. Trust offers a guarantee of the continuity of a relationship, ensuring that consumers will continue to engage in activities - resulting in co-creation $[69,16]$. Moreover, being trustworthy within a customer relationship can increase the possibility of actors investing in relational activities and increasing dependency. Therefore, actors with higher levels of trust and commitment are more likely to create perceived value in reciprocal interactions [20].

Without trust, VCD may occur because actors may be opportunism or think that others may take advantage of them and thus hesitate to provide resources and share information with other actors during the interactions $[16,17]$. On the other hand, actors may feel hurt if they trust others but not being treated fairly or with reciprocal trust. Besides, creativity is hindered with the absence of trust and it is particularly harmful for the innovation and development of industries relying heavily on creativity in co-creation, such as the media industry [60].

\subsection{Dynamic VCC \& VCD practice}

Based on the literature, we argue that VCC and VCD processes are embedded within various practices [11] that interconnect resource integration and social interaction. Frow, McColl-Kennedy and Payne [63] recognized the central role of VCC practices ('cocreation activities and interactions in a specific context') in shaping the service system by influencing the availability of resources and how resources are employed and integrated. In addition, Iyanna [64] also agreed that how respondents integrate resources into the co-creation process depends on the activities or events actors described. Based on the practice theory, Echeverri and Skålén [11] conceive that value practice can simultaneously limit and enable interactions among actors. Moreover, they identified five types of interaction value practices in public transport causing VCC and VCD namely informing; greeting; delivering; charging and helping. Access to resources within an ecosystem and the opportunities to generate interactions are effected by practices [63]. Furthermore, Tierney et al. [65] propose that the interactions and integrations exhibit mutual influence based on practices in brand meaning co-creation. It is an iterative and dynamic process in service systems rather than sequential [65].

As described by Laamanen and Skålén [36], conflicts such as VCC and VCD are neither inherently positive nor negative, but rather a dynamic process of human interaction. The constant changes to the collaborative process embedded by various practices can result in dynamic changes of outcomes. For instance, actor-driven resource integration may vary over time, depending mainly on actors' intentions, knowledge and skills, access to resources as well as the changing circumstances and context. In addition, Fyrberg Yngfalk [26] recognized that actors' interactions are not consistent, and the value creation process are continuously reformulated, adjusted, or reinforced. Therefore, VCC and VCD is a dynamically interactive process, where positive and negative outcomes strengthen or weaken as time passes.

\subsection{VCC \& VCD value outcomes}

Value is the outcome of an actor's experience of co-creation and refers to the type of outcomes that actors perceive [17]. It differs based on the actors' ability to interact, integrate resources [41], and perceive the effects of matched or mismatched practices as well as whether their expectations are met or not. Instead of a single form of VCC that all involved actors benefit from the process, interactions can result in multiple outcomes depending on the context [26]. Whether the outcome of a collaborative process is VCC or VCD depends on the actor's interpretation and assessment of value in the social context. Different actors experiencing the same cocreation or co-destruction process may hold different perceptions about value since actors interpret value based on the meanings they assign to the objects or their behaviors [66]. Therefore, value can be positive or negative, is unique to individuals, and should be assessed separately and dynamically [17].

\section{Discussion, conclusions and future research}

This paper presents a new framework for understanding the dynamic VCC and VCD processes from actors' view in service systems via a structured literature review. This is the first study to propose that VCC and VCD are triggered in the three mentioned dimensions. Specifically, actors engage in the collaboration process with different roles and behavioral drivers depending on their needs and 
expectations. Stemming from this, resource integration and social interaction take place as two key processes of co-creating and co-destructing value [26]. Whether resource integration will contribute to VCC or VCD depends on the accessibility of resources, the matching or mismatching of resources, and whether resource can be turned into benefits through operations. As dialogue, trust, and communication are essential parts of social interaction, they also contribute to VCC. Without these components, VCD may occur due to a lack of appropriate channels, shared understanding, and efficient communication. Resource integration and social interactions are iteratively interconnected by dynamic value practices, which is context-based. Value outputs are unique to individual actors, however, and therefore depends on each actor's own assessment and interpretation of the collaborative process and the effect of positive and negative value formation can change dynamically over time.

Our study contributes to the literature by presenting a systematic way of understanding VCC and VCD from actors' view in the service system. It is important since the flexibility of our framework facilitates the analysis of service systems in terms of identifying and theorizing processual phenomena [14]. In other words, it enables us to realize and better control the transition between VCC and VCD through identification and manipulation of the two core processes components through practices in order to obtain the maximum benefits for actors involved.

Our framework will also help practitioners in making decisions about service system design, marketing, and management, as it provides profound understanding of VCC and VCD process. This framework can be used as a lens to study actors' behavior so that their needs and inputs might be analyzed and put into action quickly by design and development teams. For instance, when customers feel negative about the service, the providers can use our framework to check if there is something missing during the value creation process and make adjustment accordingly, e.g. does the customers have access to resources they need (access) or does the company provide efficient channels to interact with the customers and communicate the problem (dialogue).

This study also contributes to the literature by offering a systematic overview of previous studies. Although the importance of resource integration and social integration to value creation process has been recognized by many authors, no study to date offers a summary about what have been explored and found so far and thus give a systematic insight for it. To the best of our knowledge, this is the first structured literature review to summarize how resource integration and social interaction contribute to both VCC and VCD.
This is important since an effective literature review can advance our knowledge by creating a firm foundation for further research, for instance, through facilitating theory development in actors' dynamic VCC and VCD Behavior.

As a structured literature review paper, the proposed framework is limited in its lack of empirical evidence and thus should be tested in the field to evaluate its effectiveness in explaining VCD and VCD processes. In addition, like all structured literature reviews, the breadth of this study is limited by the research design and the keywords used for retrieving the data. The processes of VCC and VCD might also be represented by other terminologies not included in the present keyword search-such as customer engagement, co-production, or service failure - to offer other interesting views on the phenomenon.

Our findings indicate several highly interesting new avenues for future research. For instance, we see that the interactive and dynamic characteristics of VCC and VCD can be very interesting for further study. What's more, when actors are going through VCD, it is important to detect the current situation and try to turn it into a co-creative one. Further research should, therefore, focus on how to identify the turning points and how to manage the transformation. This is important as such information can transform negative situation into positive with manual interventions.

Finally, we see that it would be highly interesting to study if there would be a way to reflect or measure the strength or the level of VCC and VCD since there must be a gradually changing process transforming from one to the other. This information would be valuable for managers to adopt different strategies in different phases of value creating to maximize the benefits. Towards this end, we expect to develop measurement instrument(s) for the actors' dynamic VCC and VCD behavior, which can be applied and tested in different industries in practice.

\section{References}

[1] X. Zhang and R. Q. Chen, "An empirical study on value Co-creation system by integrating customers," in Proceedings of 2007 International Conference on Management Science and Engineering, ICMSE'07 (14th), 2008, pp. 1068-1073.

[2] C. K. Prahalad and V. Ramaswamy, "Co-creation experiences: The next practice in value creation," Journal of Interactive Marketing, vol. 18, no. 3. pp. 5-14, 2004.

[3] C. Grönroos, "Conceptualising value co-creation: A journey to the 1970 s and back to the future," J. Mark. Manag., vol. 28, no. 13-14, pp. 1520-1534, 2012.

[4] R. L. Oliver, "Co-producers and co-participants in 
the satisfaction process: Mutually satisfying consumption," in The service-dominant logic of marketing: dialoge, debate, and directions, 2006, pp. $118-127$.

[5] S. L. Vargo, P. P. Maglio, and M. A. Akaka, "On value and value co-creation: A service systems and service logic perspective," Eur. Manag. J., vol. 26, no. 3, pp. 145-152, 2008.

[6] P. P. Maglio and J. Spohrer, "Fundamentals of service science," J. Acad. Mark. Sci., vol. 36, no. 1, pp. 18-20, 2008.

[7] A. Kambil, A. Ginsberg, and M. Bloch, "Reinventing value propositions," Inf. Syst. Work. Pap. Ser., p. Available at SSRN: http://ssrn.com/abstract=128482, 1996.

[8] R. F. Lusch, S. L. Vargo, and G. Wessels, "Toward a conceptual foundation for service science: Contributions from service-dominant logic," IBM Syst. J., 2010.

[9] S. Barile and M. Saviano, "An Introduction to a Value Co-Creation Model . Viability, Syntropy and Resonance in Dyadic Interaction," Syntropy, vol. 2013, no. 2, pp. 69-89, 2013.

[10] A. K. Agrawal and Z. Rahman, "Roles and Resource Contributions of Customers in Value Co-creation," Int. Strateg. Manag. Rev., vol. 3, no. 1-2, pp. 144 160, 2015.

[11] P. Echeverri and P. Skålén, "Co-creation and codestruction: A practice-theory based study of interactive value formation," Mark. Theory, vol. 11, no. 3, pp. 351-373, 2011.

[12] J. Lintula, T. Tuunanen, and M. Salo, "Conceptualizing the Value Co-Destruction Process for Service Systems: Literature Review and Synthesis," in Proceedings of the 50th Hawaii International Conference on System Sciences, 2017, pp. 1632-1641.

[13] L. Plé and R. C. Cáceres, "Not always co-creation: Introducing interactional co-destruction of value in service-dominant logic," J. Serv. Mark., vol. 24, no. 6, pp. 430-437, 2010.

[14] H. Makkonen and R. Olkkonen, "Interactive value formation in interorganizational relationships: Dynamic interchange between value co-creation, nocreation, and co-destruction," Mark. Theory, 2017.

[15] T. Vartiainen and T. Tuunanen, "Contradictions in value co-creation in it-enabled services:a case of geocaching," in 25th Australasian Conference on Information Systems, ACIS 2014, 2014.

[16] C. Grönroos and J. Gummerus, "The service revolution and its marketing implications: Service logic vs service-dominant logic," Manag. Serv. Qual., vol. 24, no.3, pp. 206-229, 2014.

[17] S. L. Vargo and R. F. Lusch, "Institutions and axioms: an extension and update of servicedominant logic," J. Acad. Mark. Sci., vol. 44, no. 1, pp. 5-23, 2016.

[18] S. Ben Letaifa, "The uneasy transition from supply chains to ecosystems: The value-creation/valuecapture dilemma," Manag. Decis., vol. 52, no. 2, pp. 278-295, 2014.
[19] F. Säwe and $\AA$ A. Thelander, "The role of frames in a co-creation process,” Int. J. Qual. Serv. Sci., vol. 7, no. 4, pp. 442-457, 2015.

[20] J. Baumann and K. Le Meunier-FitzHugh, "Making value co-creation a reality - exploring the cocreative value processes in customer-salesperson interaction," J. Mark. Manag., vol. 31, no. 3-4, pp. 289-316, 2015.

[21] S. Quach and P. Thaichon, "From connoisseur luxury to mass luxury: Value co-creation and codestruction in the online environment," J. Bus. Res., vol. 81, no. June, pp. 163-172, 2017.

[22] A. Caridà, B. Edvardsson, and M. Colurcio, "Modes of resource integration driving value co-creation: An empirical investigation in virtual brand communities (VBCs)," Proc. Naples Forum Serv., no. June, pp. 9-12, 2015.

[23] A. M. Smith, "The value co-destruction process: a customer resource perspective," Eur. J. Mark., 2013.

[24] E. Gummesson and C. Mele, "Marketing as Value Co-creation Through Network Interaction and Resource Integration," J. Bus. Mark. Manag., vol. 4, no. 4, pp. 181-198, 2010.

[25] S. L. Vargo and R. F. Lusch, "Service-dominant logic: Continuing the evolution," J. Acad. Mark. Sci., vol. 36, no. 1, pp. 1-10, 2008.

[26] A. Fyrberg Yngfalk, "'It's not us, it's them!' Rethinking value co-creation among multiple actors," J. Mark. Manag., 2013.

[27] S. K. Boell and D. Cecez-Kecmanovic, "On being 'systematic' in literature reviews," in Formulating Research Methods for Information Systems: Volume 2, 2016.

[28] J. Webster and R. T. Watson, "Analyzing the past fo prepare for the future: writing a literature review," MIS Q., 2002.

[29] S. C. Ng, C. Plewa, and J. C. Sweeney, "Professional Service Providers' Resource Integration Styles (PRO-RIS): Facilitating Customer Experiences," J. Serv. Res., vol. 19, no. 4, pp. 380395, 2016.

[30] M. R. Paredes, J. M. Barrutia, and C. Echebarria, "Resources for value co-creation in e-commerce: A review," Electron. Commer. Res., vol. 14, no. 2, pp. 111-136, 2014.

[31] A. Caridà, B. Edvardsson, and M. Colurcio, "Conceptualizing resource integration as an embedded process: Matching, resourcing and valuing," Mark. Theory, pp. 1-20, 2018.

[32] T. Chen, J. Drennan, and L. Andrews, "Experience sharing," J. Mark. Manag., vol. 28, no. 13-14, pp. 1535-1552, 2012.

[33] G. Kaur, R. Devi, and S. Sehgal, "Factors Predicting Co-creation of Value: A Study of Boutiques," Metamorph. A J. Manag. Res., 2016.

[34] C. Grönroos and P. Voima, "Critical service logic: Making sense of value creation and co-creation," J. Acad. Mark. Sci., vol. 41, no. 2, pp. 133-150, 2013.

[35] D. Ballantyne and R. J. Varey, "Creating value-inuse through marketing interaction: The exchange logic of relating, communicating and knowing," 
Mark. Theory, vol. 6, no. 3, pp. 335-348, 2006.

[36] M. Laamanen and P. Skålén, "Collective-conflictual value co-creation: A strategic action field approach," Mark. Theory, vol. 15, no. 3, pp. 381400, 2015.

[37] B. Edvardsson, B. Tronvoll, and T. Gruber, "Expanding understanding of service exchange and value co-creation: A social construction approach," J. Acad. Mark. Sci., vol. 39, no. 2, pp. 327-339, 2011.

[38] R. Findsrud, B. Tronvoll, and B. Edvardsson, "Motivation: The missing driver for theorizing about resource integration," Mark. Theory, 2018.

[39] M. Stieler, F. Weismann, and C. C. Germelmann, "Co-destruction of value by spectators: The case of silent protests," Eur. Sport Manag. Q., 2014.

[40] S. L. Vargo and R. F. Lusch, "It's all B2B...and beyond: Toward a systems perspective of the market," Ind. Mark. Manag., vol. 40, no. 2, pp. 181187, 2011.

[41] M. A. Akaka, S. L. Vargo, and R. F. Lusch, "An exploration of networks in value cocreation: A service-ecosystems view," Rev. Mark. Res., vol. 9, pp. 13-50, 2012.

[42] K. Storbacka, R. J. Brodie, T. Böhmann, P. P. Maglio, and S. Nenonen, "Actor engagement as a microfoundation for value co-creation," J. Bus. Res., vol. 69, no. 8, pp. 3008-3017, 2016.

[43] R. Gaillard, "Online co-creation of the tourist experience : A consumer perspective Exposé," 2014.

[44] S. Oreg and O. Nov, "Exploring motivations for contributing to open source initiatives: The roles of contribution context and personal values," Comput. Human Behav., 2008.

[45] S. Nambisan and R. A. Baron, "Virtual customer environments: Testing a model of voluntary participation in value co-creation activities," J. Prod. Innov. Manag., 2009.

[46] H. M. Akman, "Value co-creation in online collaborative communities: exploring the drivers and outcomes of value co-creation activities from the individual community member point of view," The university of Adelaide Business school, 2016.

[47] M. Vafeas, T. Hughes, and T. Hilton, "Antecedents to value diminution: A dyadic perspective," Mark. Theory, 2016.

[48] S. L. Vargo and R. F. Lusch, "Evolving to a New Dominant Logic for Marketing," J. Mark., vol. 68, no. 1, pp. 1-17, 2004.

[49] E. J. Arnould, L. L. Price, and A. Malshe, "Toward a Cultural Resource-Based Theory of the Customer," in The New Dominant Logic in Marketing, 2006, pp.91-104.

[50] L. Altinay, M. Sigala, and V. Waligo, "Social value creation through tourism enterprise," Tour. Manag., vol. 54, pp. 404-417, 2016.

[51] M. J. Alexander, H. Evanschitzky, and R. Murray, "Value Co-Creation: Exploring the effects of collaborating with a proactive generation of customers,"” p. 317, 2012.

[52] J. Yin, L. Qian, and J. Shen, "From value cocreation to value co-destruction? The case of dockless bike sharing in China," Transp. Res. Part D Transp. Environ., vol. 71, no. June 2018, pp. 169185,2018

[53] K. Rantala, "Professionals in Value Co-Creation through Digital Healthcare Services," University of Jyväskylä, 2018.

[54] H. Saarijärvi, "The mechanisms of value cocreation," J. Strateg. Mark., vol. 20, no. 5, pp. 381391, 2012.

[55] P. Skålén, S. Pace, and B. Cova, "Firm-brand community value co-creation as alignment of practices," Eur. J. Mark., vol. 49, no. 3-4, pp. 596620, 2015.

[56] C. Grönroos, "Towards Service Logic: The Unique Contribution of Value Co-Creation," 2009.

[57] I. O. Karpen, L. L. Bove, and B. A. Lukas, "Linking Service-Dominant Logic and Strategic Business Practice: A Conceptual Model of a ServiceDominant Orientation," J. Serv. Res., vol. 15, no. 1, pp. 21-38, 2012.

[58] C. Grönroos, "Value co-creation in service logic: A critical analysis," Mark. Theory, vol. 11, no. 3, pp. 279-301, 2011.

[59] N. Salomonson, A. Åberg, and J. Allwood, "Communicative skills that support value creation: A study of B2B interactions between customers and customer service representatives," Ind. Mark. Manag., vol. 41, no. 1, pp. 145-155, 2012.

[60] H. Järvi, Customer engagement, a friend or a foe? Investigating the relationship between customer engagement and value co-destruction. 2018.

[61] C. Moorman, R. Deshpande, and G. Zaltman, "Factors Affecting Trust in Market Research Relationships," J. Mark., vol. 57, no. 1, p. 81, 1993.

[62] H. Alves and E. Wagner Mainardes, "Self-efficacy, trust, and perceived benefits in the co-creation of value by consumers," Int. J. Retail Distrib. Manag., vol. 45, no. 11, pp. 1159-1180, 2017.

[63] P. Frow, J. R. McColl-Kennedy, and A. Payne, "Cocreation practices: Their role in shaping a health care ecosystem," Ind. Mark. Manag., 2016.

[64] S. Iyanna, "Insights into consumer resource integration and value co-creation process," J. Appl. Bus. Res., 2016.

[65] K. D. Tierney, I. O. Karpen, and K. Westberg, "Brand meaning cocreation: toward a conceptualization and research implications," J. Serv. Theory Pract., vol. 26, no. 6, pp. 911-932, 2016.

[66] T. Meynhardt, J. D. Chandler, and P. Strathoff, "Systemic principles of value co-creation: Synergetics of value and service ecosystems," J. Bus. Res., vol. 69, no. 8, pp. 2981-2989, 2016. 